\title{
Communication
}

\section{Heat Generation and Transfer Behaviors of Ti-Coated Carbon Steel Rod Adaptable for Ablation Therapy of Oral Cancer}

\author{
Takashi Naohara ${ }^{1}{ }^{*}$, Hiromichi Aono ${ }^{1}$, Tsunehiro Maehara ${ }^{1}$, Hideyuki Hirazawa ${ }^{2}$, \\ Shinya Matsutomo ${ }^{3}$ and Yuji Watanabe ${ }^{4}$
}

1 Graduate School of Science and Engineering, Ehime University, Matsuyama 790-8577, Japan;

E-Mails: aono.hiromichi.mf@ehime-u.ac.jp (H.A.); maehara.tsunehiro.mg@ehime-u.ac.jp (T.M.)

Department of Environmental Materials Engineering, Niihama National College of Technology, Niihama 792-8580, Japan; E-Mail: hirazawa@mat.niihama-nct.ac.jp

3 Department of Electronic Control Engineering, Niihama National College of Technology, Niihama 792-8580, Japan; E-Mail: shin@ect.niihama-nct.ac.jp

4 Department of Surgery, Graduate School of Medicine, Ehime University, Toon 791-0295, Japan; E-Mail: yuji@m.ehime-u.ac.jp

* Author to whom correspondence should be addressed; E-Mail: naohara.takashi.mu@ehime-u.ac.jp; Tel./Fax: +81-89-927-9897.

Received: 25 December 2012; in revised form: 23 January 2013 / Accepted: 25 January 2013 / Published: 18 February 2013

\begin{abstract}
For the purpose of developing a novel ablation therapy for oral cancer, the heat generation and transfer properties of a Ti-coated carbon steel rod with $20-\mathrm{mm}$ length and $1.8-\mathrm{mm}$ outer diameter were investigated by means of a high-frequency induction technique at $300 \mathrm{kHz}$. The heat generation measurement performed using water $(15 \mathrm{~mL})$ revealed that the difference of the inclination angles $\left(\theta=0^{\circ}, 45^{\circ}\right.$ and $\left.90^{\circ}\right)$ relative to the magnetic flux direction only slightly affects the heating behavior, exhibiting the overlapped temperature curves during an induction time of $1200 \mathrm{~s}$. These results suggest that the effect of the shape magnetic anisotropy is almost eliminated, being convenient for the precise control of the ablation temperature in clinical use. In the experiments utilizing a tissue-mimicking phantom, the heat transfer concentrically occurred in the lateral direction for both the planar surface and a 10-mm deep cross-section. However, the former exhibited a considerably lower increase in temperature $(\Delta \mathrm{T})$, probably due to the effect of heat
\end{abstract}


dissipation to the ambient air. No significant heat transfer was found to occur to the lower side of the inserted Ti-coated carbon steel rod, which is situated in the longitudinal direction.

Keywords: cancer therapy; ablation treatment; high-frequency induction technique; tissue-mimicking phantom; heat transfer simulation; magnetic flux direction

\section{Introduction}

Oral cancer is a malignant growth that affects any part of the oral cavity, including the lips, tongue, gums, floor of the mouth and palate [1-3]. For patients with oral cancer, the treatment option depends on various factors, such as where the cancer is, its stage and the patient's general health. As well accepted, there are three main options for the oral cancer treatment [4,5]. Surgical resection is a medical procedure aimed to completely remove the tumor tissue together with adjacent healthy tissue in order to prevent a future cancer relapse [5,6]. However, this option is frequently associated with disfigurement and dysfunction, such as speech impairment, dysphagia and aspiration [7,8]. If these side effects cannot be corrected or minimized, the patients may undergo a substantial decrease in the quality of life. Radiotherapy uses high-energy rays or particles to destroy the cancerous cells. The purpose of this treatment is to destroy cancerous tissues, while preserving the healthy tissue, and the side effects mainly depend on the radiation dosage and the targeted area. The most common side effects displayed by oral cancer patients that undergo radiotherapy are mucositis, taste loss, xerostomia, hyposalivation, etc. [9-11]. Chemotherapy is usually not used alone to stop oral cancer, but as an adjunct to surgery and/or radiotherapy [12]. In particular, the patients with locally recurrent or metastatic oral cancer receive this treatment, which results in a better survival benefit [13]. This treatment option also has the ability to interfere with the cancerous cell replication; however, their side effects include mucositis oral infections, dysgeusia, and oral bleeding, together with temporary alopecia [14-16].

In addition to these conventional treatments of oral cancer, the clinical application of a novel option has been desired from the viewpoint of organ conservation in combination with fewer side effects. For patients with oral cancer, it is particularly essential to minimize the cosmetic and functional impairments for a better prognostic quality of life.

In the present study, we attempted to develop an ablation needle adaptable to the oral cancer therapy utilizing a high-frequency induction technique [17]. It should be emphasized that this thermotherapy is suitable for superficial cancer, due to the easy insertion of the ablation needle into the tumors. Hence, the heat generation and transfer behaviors of a Ti-coated carbon steel rod were experimentally investigated by employing water $(15 \mathrm{~mL})$ and a tissue-mimicking phantom. The computer simulation of the heat transfer was also carried out to visualize the temperature distribution in the tissue-mimicking phantom subjected to the insertion of the Ti-coated carbon steel rod. 


\section{Materials and Methods}

\subsection{Preparation of the Sample and Tissue-Mimicking Phantom}

Table 1 shows the ingredients used to prepare the tissue-mimicking phantom together with their weights and ratios. As seen in the table, the tissue-mimicking phantom was made of agar, polyethylene powder, sodium chloride $(\mathrm{NaCl})$, boric acid and TX-151 in addition to deionized water [18,19]. Agar was used to hold the phantom shape by preventing separation of the water-soluble contents. The TX-151 was used as a thickener to mix the agar solution and the polyethylene powder, while the boric acid was employed as a preservative. The measured quantities of these ingredients were added to hot deionized water and stirred to make a uniform solution. The mixture was then poured into a plastic container and allowed to cool at room temperature. A small cylindrical section was removed from this square-shaped tissue-mimicking phantom for the following heat transfer experiments.

In a previous paper [20], we reported the heating properties of a carbon steel rod embedded into Ti-tubes of various inner diameters in a high-frequency induction field at $300 \mathrm{kHz}$. Based on the previous experiments, there was an optimum thickness to minimize the effect of the inclination angle relative to the magnetic flux direction. The optimum Ti-tube had a 1.8-mm outer diameter and 1.0-mm inner diameter, which was used in the present study. A ferromagnetic carbon steel rod with a $20-\mathrm{mm}$ length was embedded in the Ti-tube to form the rod-like specimen.

Table 1. The ingredients, their weights and ratios used for the preparation of the tissue-mimicking phantom in the present study.

\begin{tabular}{ccc}
\hline Ingredient & Weight $(\mathbf{g})$ & Ratio $(\%)$ \\
\hline Deionized water & 365.0 & 74.8 \\
Agar & 20.0 & 4.1 \\
Polyethylene powder & 70.0 & 14.4 \\
Sodium chloride $(\mathrm{NaCl})$ & 7.9 & 1.6 \\
Boric acid & 7.9 & 1.6 \\
TX-151 & 16.9 & 3.5 \\
\hline
\end{tabular}

\subsection{Experimental Procedures}

Figure 1 shows the partial experimental set up around the specimen placed in a high-frequency induction coil for the different measuring conditions. The increase in temperature $(\Delta T)$ was measured in water $(15 \mathrm{~mL})$ to estimate the heat generation ability using a radiation thermometer at three different angles of $\theta=0^{\circ}, 45^{\circ}$ and $90^{\circ}$ relative to the magnetic flux direction (Figure 1a). To clarify the heat transfer behavior, the $\Delta \mathrm{T}$ value of the tissue-mimicking phantom subjected to the $\theta=0^{\circ}$ specimen insertion was also measured using a radiation thermometer and a fiber-optic thermometer (Figure 1b). The magnetic field and frequency were $1.69 \mathrm{kA} / \mathrm{m}$ and $300 \mathrm{kHz}$, respectively, for both measuring conditions.

Figure 2 shows the entire experimental setup used for the measurement of the heat generation and transfer behaviors in the high-frequency induction field at $300 \mathrm{kHz}$. The high-frequency induction coil was connected to a power supply through an impedance matching box. The tissue-mimicking phantom subjected to the $\theta=0^{\circ}$ specimen insertion is schematically illustrated in the figure for a more detailed 
explanation. The heat transfer behavior was investigated for both the planar surface and the 10-mm deep cross-section of the tissue-mimicking phantom using a radiation thermometer and a fiber-optic thermometer.

Figure 1. Partial experimental set up showing the specimen placed in a high-frequency induction coil to measure the heating behaviors $(\mathbf{a})$ in water $(15 \mathrm{~mL})$ and $(\mathbf{b})$ tissue-mimicking phantom at different inclination angles relative to the magnetic flux direction.
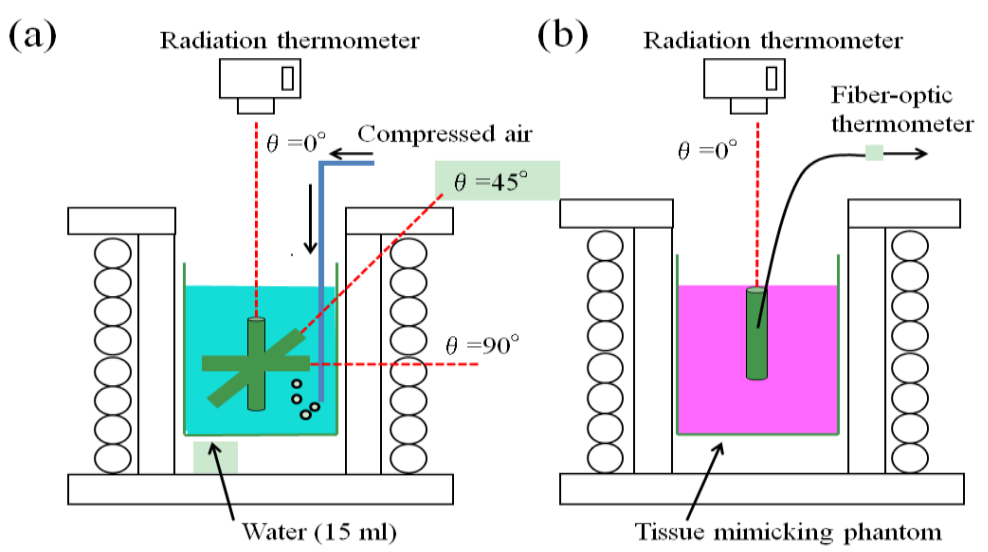

Figure 2. Complete experimental setup for measuring the heat transfer behavior of the tissue-mimicking phantom subjected to the insertion of the Ti-coated carbon steel rod in the high-frequency induction field of $1.69 \mathrm{kA} / \mathrm{m}$ at $300 \mathrm{kHz}$.

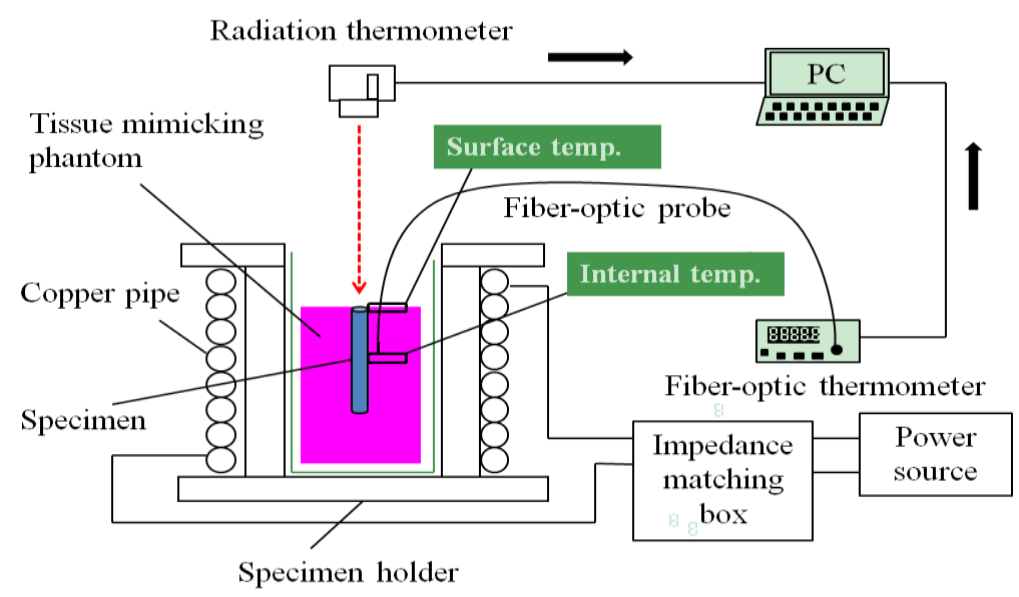

Figure 3 shows the three-dimensional and two-dimensional appearances of the cylindrical tissue-mimicking phantom subjected to the $\theta=0^{\circ}$ specimen insertion. The specimen with a $1.8-\mathrm{mm}$ outer diameter and 20-mm length was vertically inserted at the center of the planar surface into the cylindrical tissue-mimicking phantom with a $20-\mathrm{mm}$ diameter and 30-mm height. As seen in the figure, the $\Delta \mathrm{T}$ value was measured from the contact position $(\mathrm{d}=0 \mathrm{~mm})$ to a 8 - $\mathrm{mm}$ distant position $(\mathrm{d}=8 \mathrm{~mm})$ at $1-\mathrm{mm}$ intervals for both the planar surface and 10-mm deep cross-section. A fiber-optic thermometer was used to directly measure the inside $\Delta \mathrm{T}$ value of the tissue-mimicking phantom, as shown in Figure 2. 
Figure 3. (a) Three-dimensional; (b) and two-dimensional schematic views of the cylindrical tissue-mimicking phantom subjected to the insertion of the Ti-coated carbon steel rod. The temperature measuring points are denoted by the red circles.

(a)

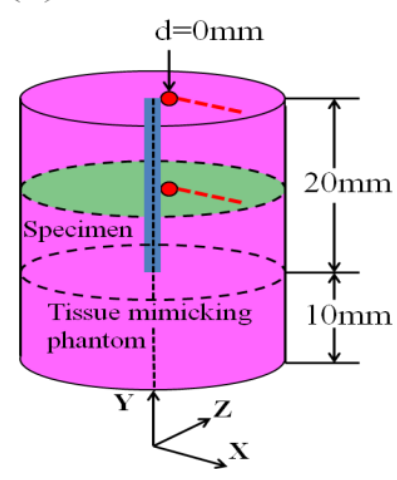

(b)

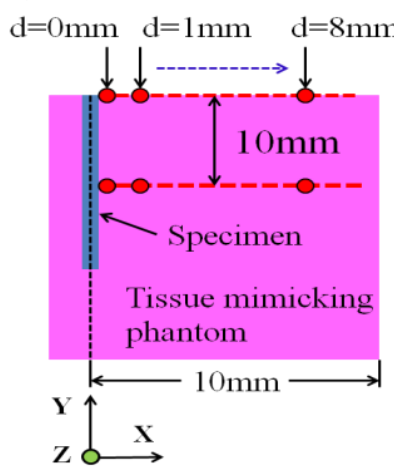

\subsection{Computer Simulation of Heat Transfer in the Tissue-Mimicking Phantom}

The heat transfer behavior was simulated for the tissue-mimicking phantom subjected to the insertion of the Ti-coated carbon steel rod. Heat analysis software, JMAG Studio, ver. 10.0 (JRI Solutions, Ltd., Tokyo, Japan), was employed to visualize the temperature distribution in both the lateral and longitudinal directions. The simulation model was created by considering the physical parameters of the carbon steel rod, Ti-tube and tissue-mimicking phantom, as well as their size, frequency, current condition and turn number of the coil. The relative magnetic permeability value of the ferromagnetic carbon steel rod used in the simulation was 2,000, while this value was 1 for the non-magnetic Ti-tube. The three-dimensional and two-dimensional models used in the present study are presented in Figure 4.

Figure 4. Computer simulation model of heat transfer drawn (a) three-dimensionally;

(b) and two-dimensionally, used in the present study.
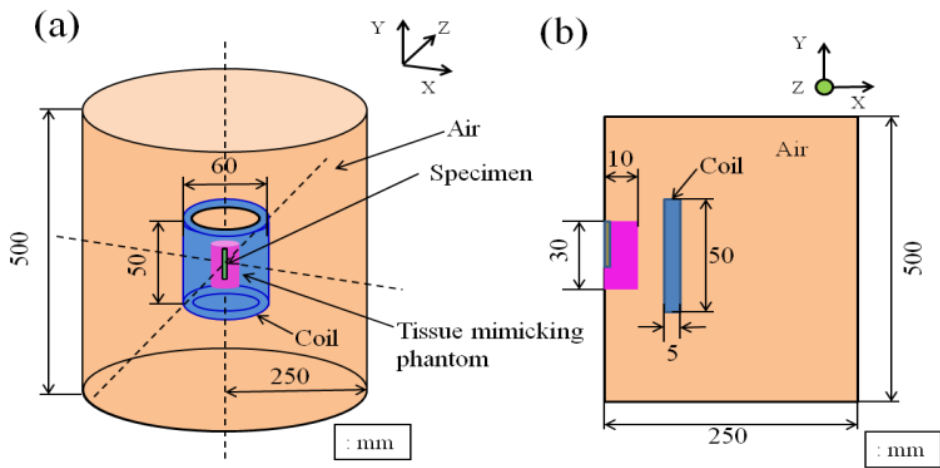

\section{Results and Discussion}

\subsection{Heat Generation Ability of the Ti-Coated Carbon Steel Rod}

Figure 5 shows the relationship between the increase in temperature $(\Delta \mathrm{T})$ of water $(15 \mathrm{~mL})$ and induction time for the Ti-coated carbon steel rod in the high-frequency field of $1.69 \mathrm{kA} / \mathrm{m}$ at $300 \mathrm{kHz}$. 
Both the $\theta=0^{\circ}$ and $\theta=90^{\circ}$ specimens exhibit overlapping temperature curves that reach the $\Delta \mathrm{T}$ value of $4.8{ }^{\circ} \mathrm{C}$ after $1,200 \mathrm{~s}$. The $\Delta \mathrm{T}$ similarly increases with the increasing induction time, and its value reached $5.0{ }^{\circ} \mathrm{C}$ after $1,200 \mathrm{~s}$ for the $\theta=45^{\circ}$ specimen. It is important to note that the non-oriented heating property relative to the magnetic flux direction is achieved for the measurement in water $(15 \mathrm{~mL})[20]$. In the novel thermotherapy, the injection direction of the ablation needle seems to significantly vary due to the tumor location. A non-oriented heating property relative to the magnetic flux direction is indispensable for the precise control of the treatment temperature. However, the shape magnetic anisotropy, which originates from the demagnetizing field coefficient, results in an undesirable effect on the heating properties in the high-frequency induction field [21]. Thus, the present Ti-coated carbon steel rod appears to have a high potential as the ablation needle for a novel oral cancer treatment [17]. The heat generation ability was calculated using the temperature enhancement ratio during the initial $120 \mathrm{~s}$ of the $\Delta \mathrm{T}$ measurement. These values were $1.50,1.37$ and $1.12 \mathrm{~W} / \mathrm{g}$ for the $\theta=45^{\circ}, \theta=90^{\circ}$ and $\theta=0^{\circ}$ specimens, respectively, as denoted in the figure. It is noted that the difference in these values only slightly affects the heating behavior of water $(15 \mathrm{~mL})$. According to the report by Yamada et al. [22], the heating of the cancer cells up to $50{ }^{\circ} \mathrm{C}$ for $600 \mathrm{~s}$ is sufficient for complete cell killing, and the heat dose of 1.70 $\mathrm{W} / \mathrm{g}$ is required for a $10-\mathrm{mm}$ size tumor. Considering the influence of the body temperature (approximately $37.0^{\circ} \mathrm{C}$ ), the $\Delta \mathrm{T}$ value of $10.0{ }^{\circ} \mathrm{C}$ after $1,200 \mathrm{~s}$ appears to be a criterion for the effective ablation treatment of oral cancer. It appears that the Ti-coated carbon steel rod used in the present study possesses the potential to be the ablation needle for this novel oral cancer therapy.

Figure 5. Changes in temperature of water $(15 \mathrm{~mL})$ for the Ti-coated carbon steel rod at different inclination angles relative to the magnetic flux direction versus the induction time in the high-frequency induction field of $1.69 \mathrm{kA} / \mathrm{m}$ at $300 \mathrm{kHz}$.

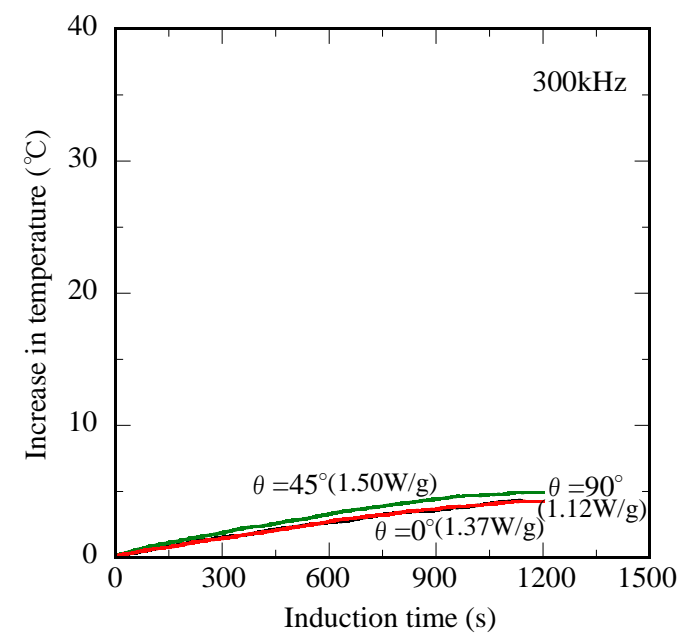

\subsection{Heat Transfer Behavior of the Tissue-Mimicking Phantom}

Figure 6 shows the induction time dependence of the heat transfer behavior for the tissue-mimicking phantom at the $10-\mathrm{mm}$ deep cross-section. The measured temperature increases continuously with the induction time and reached $\Delta \mathrm{T}=19.8{ }^{\circ} \mathrm{C}$ after $1,200 \mathrm{~s}$ at the contact position $(\mathrm{d}=0 \mathrm{~mm})$. A similar induction time dependence of $\Delta \mathrm{T}$ is obtained from the other temperature curves; however, the $\Delta \mathrm{T}$ after $1,200 \mathrm{~s}$ gradually decreases with the increasing distance from the contact 
position $(\mathrm{d}=0 \mathrm{~mm})$. For instance, the $\Delta \mathrm{T}$ values after $1,200 \mathrm{~s}$ are $12.0{ }^{\circ} \mathrm{C}$ and $9.9{ }^{\circ} \mathrm{C}$ at the $\mathrm{d}=4 \mathrm{~mm}$ position and $\mathrm{d}=8 \mathrm{~mm}$ position, respectively.

Figure 6. Changes in temperature of the tissue-mimicking phantom with different distances from the contact position $v s$. the induction time at the 10-mm deep cross-section.

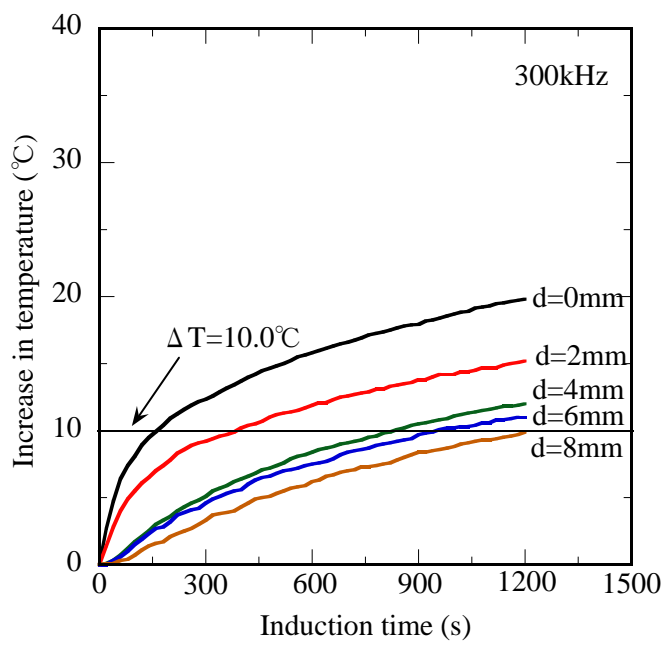

The relationship between the increase in temperature $(\Delta \mathrm{T})$ after 1,200 $\mathrm{s}$ and distance from the contact position is presented in Figure 7 for both the planar surface and 10-mm deep cross-section. In the $10-\mathrm{mm}$ deep cross-section, the $\Delta \mathrm{T}$ of the $\mathrm{d}=0 \mathrm{~mm}$ position is $19.8{ }^{\circ} \mathrm{C}$, and its value reached $\Delta \mathrm{T}=9.9^{\circ} \mathrm{C}$ at the $\mathrm{d}=8 \mathrm{~mm}$ position, showing the gradual decrease with the increasing distance from the contact position $(\mathrm{d}=0 \mathrm{~mm})$. However, the $\Delta \mathrm{T}$ is $10.0^{\circ} \mathrm{C}$ at the $\mathrm{d}=0 \mathrm{~mm}$ position for the planar surface, while its value is at most $4.0{ }^{\circ} \mathrm{C}$ after the induction time of $1,200 \mathrm{~s}$ at the $\mathrm{d}=8 \mathrm{~mm}$ position. Hence, the $\Delta \mathrm{T}$ of the planar surface exhibits a lower value than those of the 10-mm deep cross-section. It is appropriate to consider that a significant heat dissipation takes place from the planar surface of the tissue-mimicking phantom to the ambient air.

Figure 7. Changes in temperature of the tissue-mimicking phantom obtained at the planar surface and the 10-mm deep cross-section after 1,200 s vs. the distance from the contact position.

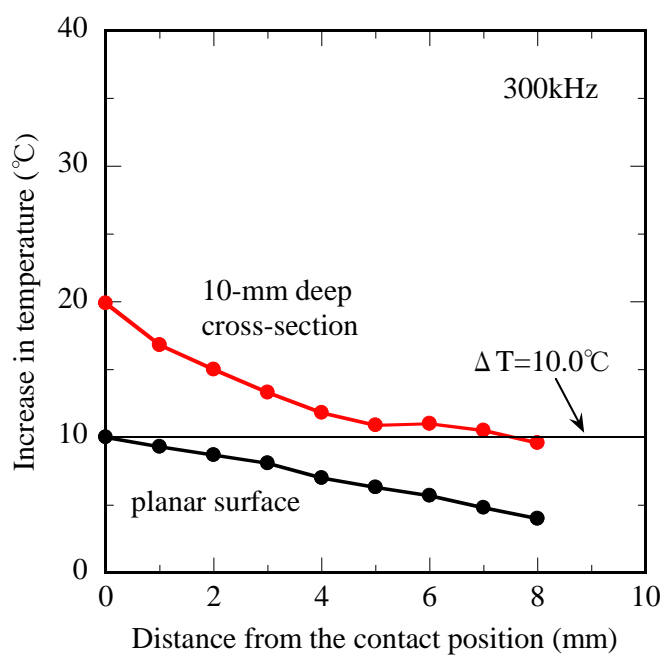




\subsection{Heat transfer Simulation Images of the Tissue-Mimicking Phantom}

Figure 8 shows the heat transfer simulation images of the tissue-mimicking phantom taken for the longitudinal section using a $180^{\circ}$ simulation model. The temperature distribution is colored light green (Figure 8a) at the initial temperature of $20.0{ }^{\circ} \mathrm{C}$, which corresponds to the $\Delta \mathrm{T}=0{ }^{\circ} \mathrm{C}$ for all planes. However, the generated heat transfers in the lateral direction (Figure 8b) during the induction time of $1200 \mathrm{~s}$. Taking note of the longitudinal section, it spreads more widely around the middle position of the inserted 20-mm long specimen, while no significant heat transfer occurs to the underside of the specimen. It is concluded from these results that we cannot expect any ablation effect to the underside of the inserted ablation needle.

Figure 8. Heat transfer simulation images showing the temperature distribution at (a) $0 \mathrm{~s}$ and (b) after 1,200 s in the longitudinal section of the tissue-mimicking phantom.

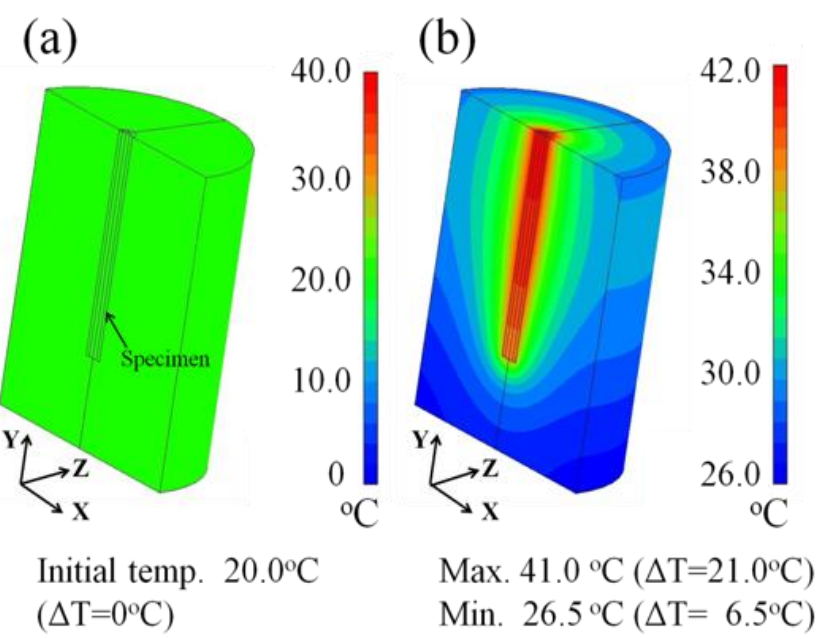

Figure 9 shows the heat transfer images of the tissue-mimicking phantom subjected to the $\theta=0^{\circ}$ specimen insertion for the 10-mm deep cross-section obtained after $1200 \mathrm{~s}$. As seen in Figure 9a, the temperature distribution is colored light-green at the initial temperature of $20.0{ }^{\circ} \mathrm{C}$. It is obvious from Figure $9 \mathrm{~b}$ that the generated heat concentrically spreads during the induction time of $1200 \mathrm{~s}$, showing the color transition as colored dark red, light green and light-gray blue and gray-blue. In addition, the simulated maximum temperature and the resultant $\Delta \mathrm{T}$ value at the $10-\mathrm{mm}$ deep cross-section are $41.0{ }^{\circ} \mathrm{C}$ and $21.0^{\circ} \mathrm{C}$, respectively, as denoted in the lower side of Figure $9 \mathrm{~b}$. Referring to the color display bar on the right side, the outer region of the concentric circle ranging from a $7-\mathrm{mm}$ to 10 -mm radius is colored gray-blue, suggesting that the temperature reaches $30.0^{\circ} \mathrm{C}$ during the induction time of $1,200 \mathrm{~s}$ and the resultant $\Delta \mathrm{T}$ value is approximately $10.0^{\circ} \mathrm{C}$. In comparison to Figure 7 , we note that there is a good agreement between the experimental and simulated data for the 10-mm deep cross-section of the tissue-mimicking phantom. 
Figure 9. Heat transfer simulation images showing the temperature distribution at (a) $0 \mathrm{~s}$ and (b) after 1,200 s in the 10-mm deep cross-section of the tissue-mimicking phantom.
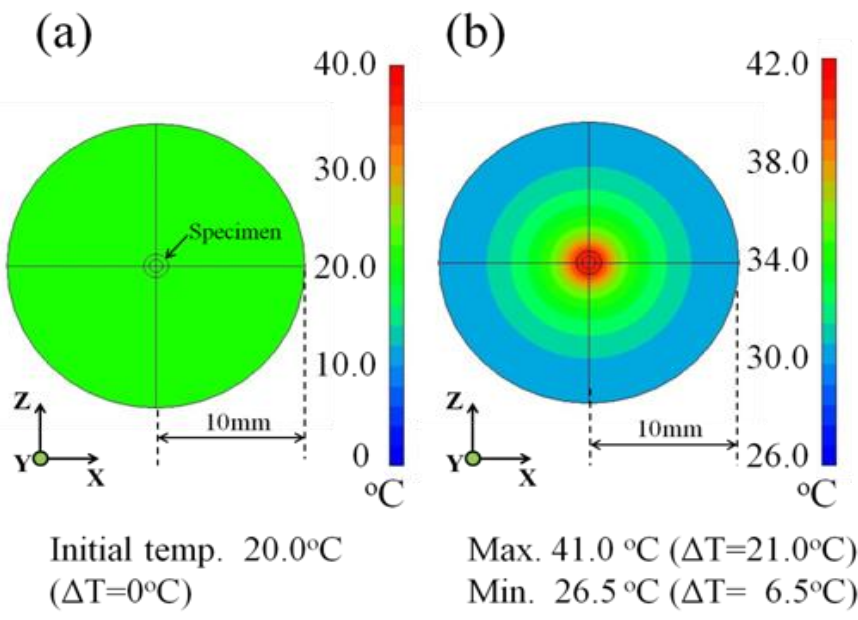

\section{Conclusions}

With the aim of estimating the applicability as a novel ablation therapy for oral cancer, the heat generation and transfer behaviors of a Ti-coated carbon steel rod were investigated using both water $(15 \mathrm{~mL})$ and a tissue-mimicking phantom in a high-frequency induction field at $300 \mathrm{kHz}$. The non-oriented heating property was achieved for the measurement using water $(15 \mathrm{ml})$ by changing the inclination angles $\left(\theta=0^{\circ}, \theta=45^{\circ}\right.$ and $\left.\theta=90^{\circ}\right)$ relative to the magnetic flux direction. In the heat transfer experiments employing the tissue-mimicking phantom, the $\Delta \mathrm{T}$ value gradually decreased with the increasing distance from the contact position to an $8-\mathrm{mm}$ distance for both the planar surface and 10 -mm deep cross-section. However, the former exhibited significantly lower values than the latter through the distance up to 8-mm, probably due to the heat dissipation from the planar surface to the ambient air. The concentric heat spread in the lateral direction was visualized by the heat transfer simulation images. Furthermore, no significant heat transfer was found to occur to the underside of the specimen, which is situated in the longitudinal direction. Based on these results, it seems likely that the Ti-coated carbon steel rod possesses a high potential as an ablation needle for treating superficial oral cancer.

\section{Acknowledgment}

The present study was supported by a Grant-in-Aid from The Ministry of Education, Science, Sports and Culture of Japan (No.23500559: T. Naohara).

\section{References}

1. Neville, B.W.; Day, T.A. Oral cancer and precancerous lesions. CA Cancer J. Clin. 2002, 52, 195-215.

2. MacCarthy, D.; Flint, S.R.; Healy, C.; Stassen, L.F. Oral and neck examination for early detection of oral cancer-A practical guide. J. Ir. Dent. Assoc. 2011, 57, 195-199.

3. Werning, J.W. Oral Cancer: Diagnosis, Management, and Rehabilitation; Thieme Medical Publishers, Inc.: New York, NY, USA, 2007; pp. 38-41. 
4. Sciubba, J.J. Oral cancer: The importance of early diagnosis and treatment. Am. J. Clin. Dermatol. 2001, 2, 239-251.

5. Scully, C.; Bagan, J.V. Recent advances in oral oncology 2007: Imaging, treatment and treatment incomes. Oral Oncol. 2008, 44, 211-215.

6. Yao, M.; Epstein, J.B.; Modi, B.J.; Pytynia, K.B.; Mundt, A.J.; Feldman, L.E. Current surgical treatment of squamous cell carcinoma of the head and neck. Oral Oncol. 2007, 43, 213-223.

7. Kronenberger, M.B.; Meyers, A.D. Dysphagia following head and neck cancer surgery. Dysphagia 1994, 9, 236-244.

8. Davies, A.; Epstein, J. Oral Complications of Oral Cancer and Its Management; Oxford University Press: New York, NY, USA, 2010; pp. 80-82.

9. Sonis, S.T. Oral mucositis in cancer therapy. J. Support. Oncol. 2004, 2, 3-8.

10. Vissink, A.; Jansma, J.; Spijkervet, F.K.; Burlage, F.R.; Coppes, R.P. Oral sequelae of head and neck radiotherapy. Crit. Rev. Oral Biol. Med. 2003, 14, 199-212.

11. Dreizen, S.; Daly, T.E.; Drane, J.B.; Brown, L.R. Oral complication of cancer radiotherapy. Postgrad. Med. 1977, 61, 85-92.

12. Burri, R.J.; Lee, N.Y. Concurrent chemotherapy and radiotherapy for head and neck cancer. Expert Rev. Anticancer Ther. 2009, 9, 293-302.

13. Molin, Y.; Fayette, J. Current chemotherapies for recurrent/metastatic head and neck cancer. Anticancer Drugs 2011, 22, 621-615.

14. Chaveli Lopez, B.; Gavalda Esteve, C.; Sarrion Perez, M.G. Dental treatment consideration in the chemotherapy patient. J. Clin. Exp. Dent. 2011, 3, e31-e42.

15. Lionel, D.; Christophe, L.; Marc, A.; Jean-Luc, C. Oral mucositis induced by anticancer treatments: Physiopathology and treatments. Ther. Clin. Risk Manag. 2006, 2, 159-168.

16. Dąbrowski, T. Hair loss as a consequence of cancer chemotherapy-Physical methods of prevention. A review of the literature. Contemp. Oncol. 2011, 15, 95-101.

17. Naohara, T.; Aono, H.; Maehara, T.; Hirazawa, H.; Matsutomo, S.; Watanabe, Y. Development of Ti-coated ferromagnetic needle adaptable for ablation cancer therapy by high-frequency induction heating. J. Funct. Biomater. 2012, 3, 163-172.

18. Furuya, K.; Hamada, L.; Ito, K.; Kasai, H. A new muscle-equivalent phantom for SAR estimation. IEICE Trans. Commun. 1995, E78, 871-873.

19. Onishi, T.; Ishido, R.; Takimoto, T.; Saito, K.; Uebayashi, S.; Ito, K. Biological tissue-equivalent agar-based solid phantom and SAR estimation using the thermographic method in the range of 3-6 GHz. IEICE Trans. Commun. 2005, E88-B, 3733-3741.

20. Naohara, T.; Aono, H.; Hirazawa, H.; Maehara, T.; Watanabe, Y.; Matsutomo, S. Heat generation ability in AC magnetic field of needle-type Ti-coated mild steel for ablation cancer therapy. Int. J. Comput. Math. Electr. Electron. Eng. 2011, 30, 1582-1588.

21. Cullity, B.D.; Graham, C.D. Introduction to Magnetic Materials; Willey IEEE Press: Hoboken, NJ, USA, 2008; pp. 234-237. 
22. Yamada, K.; Oda, T.; Hashimoto, S.; Enomoto, T.; Ohkohchi, N.; Ikeda, H.; Yanagihara, H.; Kishimoto, M.; Kita; E.; Tasaki, A.; Satake, M.; Ikehata, Y.; Nagae, H.; Nagano, I.; Takagi, T.; Kanamori, T. Minimally required heat doses for various tumor sizes in induction heating cancer therapy determined by computer simulation using experimental data. Int. J. Hyperthermia 2010, 26, 465-474.

(C) 2013 by the authors; licensee MDPI, Basel, Switzerland. This article is an open access article distributed under the terms and conditions of the Creative Commons Attribution license (http://creativecommons.org/licenses/by/3.0/). 